\title{
Effect of hydrodynamics factors on flocculation processes in estuaries
}

\author{
A. Mhashhash; B. Bockelmann-Evans and S. Pan \\ School of Engineering, Cardiff University, mhashhashAF1@ cardiff.ac.uk
}

\begin{abstract}
Cohesive sediment flocculates under certain conditions to form flocs which are larger than individual particles and less dense. The flocculation has an important role in sediment transport processes of settling, deposition and erosion. In this study, well controlled laboratory experiments were performed to investigate the effect of turbulence on floc size and settling velocity. Experimental research was conducted in a $1 \mathrm{~L}$ glass beaker of $11 \mathrm{~cm}$ diameter using suspended sediment samples taken from the Severn Estuary. A PIV system and image processing routine were used to measure the floc size distribution and settling velocity, as well as the flocs density. This study found that turbulent shear stress in a range from 0.57 to $8.5 \mathrm{~N} / \mathrm{m}^{2}$ would cause a breakdown in floc structure. The settling velocity of the samples was found to range from 0.4 to 1.4 $\mathrm{mm} / \mathrm{s}$. The average settling velocity increased with the increase of the turbulent shear stress up to the maximum value $(1.1 \mathrm{~mm} / \mathrm{s})$, and then decreased. It was also found that the relationship between floc size and turbulence were independent of the history of the floc formation.
\end{abstract}

\section{INTRODUCTION}

Cohesive sediments are regarded as one of the most important features of estuaries around the world. The sediment size of the cohesive sediment is normally in a range of 2- $63 \mu \mathrm{m}$. Under certain conditions, these sediments flocculate to form large aggregates, namely flocs, which are larger than individual particles but less dense. This flocculation phenomenon has a strong influence on the sediment transport processes of deposition, erosion and settling (Fennessy et al. 1994).

In general, flocs were classified as two types, namely, microflocs and macroflocs, whereas cohesive sediment flocculates to form small microflocs first, and then macroflocs by combining the microflocs (Eisma 1986). Microflocs can be classified as those aggregates which do not exceed a spherically equivalent diameter of $100 \mu \mathrm{m}$ (Lafite 2001) and have a settling velocity of less than $1 \mathrm{~mm} / \mathrm{s}$. The state of microflocs continually changes in response to the hydrodynamic, and the physico-chemical and environmental conditions. These microflocs can develop into large, but low dense flocs called macroflocs which behave very differently. Macroflocs have a diameter larger than $100 \mu \mathrm{m}$ and a settling velocity between $1-15 \mathrm{~mm} / \mathrm{s}$ (Fennessy et al. 1994; Manning and Dyer 1999; Manning 2001; Manning et al. 2013).
Flocculation of the fine sediments can occur with two different mechanisms: one is to bring the particles to direct contact by turbulence; and the other is to stick the flocs together by electrostatic charging e.g. organic matter content and salinity (Dyer and Manning 1999). The flocculation process mainly occurs in the very low salinity region (between 1 and $2.5 \mathrm{ppt}$ ) (Wollast 1988), and it is affected by hydrodynamic changes which can alter the suspended sediment particle by modifying its effective particle size, shape, porosity, density and composition. $\mathrm{Nu}-$ merous studies have been carried out to investigate the flocculation phenomenon in the laboratory, such as (Serra et al. 1997; Manning and Dyer 1999; Mikes et al. 2004; Maggi 2005) and in situ (Fennessy et al. 1994; Syvitski et al. 1995; van Leussen and Cornelisse 1996). Due to the complexity of the natural system, many simplifications are made in laboratory studies in order to control the different variable parameters in the flocculation process. Natural flocculation processes are difficult to be reproduced in laboratory experiments due to the complexity of processes involved. However, the laboratory experiments are valuable for investigating systematically the effect of specific parameters such as salinity, suspended sediment concentration and turbulence under controlled conditions (Manning 
2004b; Manning et al. 2004; Mikes et al. 2004). One of the main parameters for studying the flocculation process in laboratory experiments is the turbulence, which is used to create conditions as close to the natural estuarine environment as possible. Examining floc distribution under changing turbulent shear rate may lead to multiple cycles of growth, break up, and regrowth that produce conditions are, to some extent, similar to situ measurement.

Four different devices, namely the jar test (Mikes et al. 2004), annular flume (Dyer and Manning 1999), sedimentation column and turbulence grid (Maggi 2005), and the Couette device with a video camera system (Serra et al. 1997; Serra and Casamitjana 1998) have been used for generating turbulence and flocculation in laboratory experiments. The development of the latter technology (video technology) has allowed obtaining both floc size and settling velocity spectra. In this study, a laboratory video analysis method was developed to measure the size of the flocs. This instrumental setup requires little equipment and is easy to implement in the laboratory. It consists of a glass bowl, CCD camera and variable speed agitator control for the turbulent shear stress inside the bowl. The floc size can then be measured under varying turbulence conditions.

The aim of this study is to experimentally determine the effect of turbulence as one of the key hydrodynamic parameters, on the flocculation phenomenon. Floc size and settling velocities are measured during these experiments.

\section{MATERIALS AND METHODS}

\subsection{Overview of study area}

The Severn Estuary, located between South East Wales and South West England, is the largest tidal estuary in the UK and has the third highest tidal range in the world with a spring tide of up to $14.7 \mathrm{~m}$ (Kadiri 2014). The estuary generates high currents that exceed $3 \mathrm{~m} / \mathrm{s}$ (Gao et al. 2011). The river system has a total catchment area of approximately $25,000 \mathrm{~km}^{2}$ (Jonas and Millward 2010) and the estuary has a total channel length of $137 \mathrm{~km}$. The major tributaries of the Severn are the Usk, Wye (on the Welsh side) and the Stour (on the English side). The tidal range varies significantly along the estuary and over time. The average spring and neap tidal ranges are $12.3 \mathrm{~m}$ and $6.5 \mathrm{~m}$, respectively (Kirby 2010). The annual suspended sediment load has been approximated at $1.6 \times 10^{9} \mathrm{~kg} /$ year; nearly $1.25 \times 10^{9} \mathrm{~kg} /$ year of which is discharged from the rivers Wye, Avon and Severn (McLaren et al. 1993).
Flocculation phenomenon was studied in the laboratory using suspended sediment from the Severn Estuary. Samples were collected from 'Slipway' in the proximity of the New Severn Bridge as shown in Figure 1. Data acquisition took place on 1 June 2014, sampling at around the high tide mark of 9.5 m.

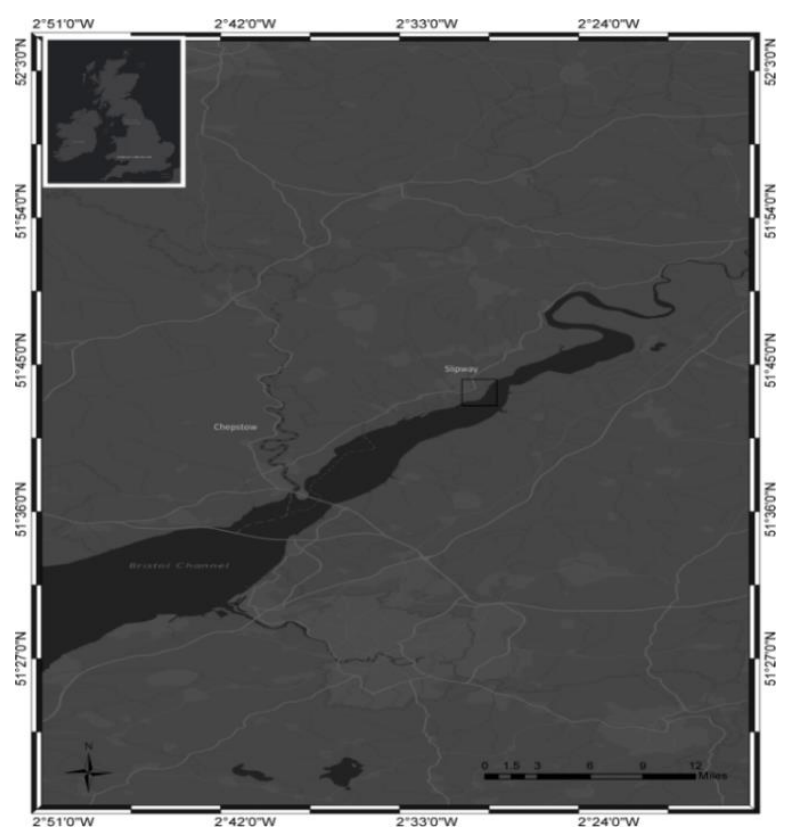

Figure 1. Map of Severn Estuary showing the location of sampling sites, Slipway ( $\left.2^{\circ} 30^{\circ} 00.67^{\prime \prime} \mathrm{N}, 51^{\circ} 42^{`} 52.12^{\prime \prime} \mathrm{W}\right)$.

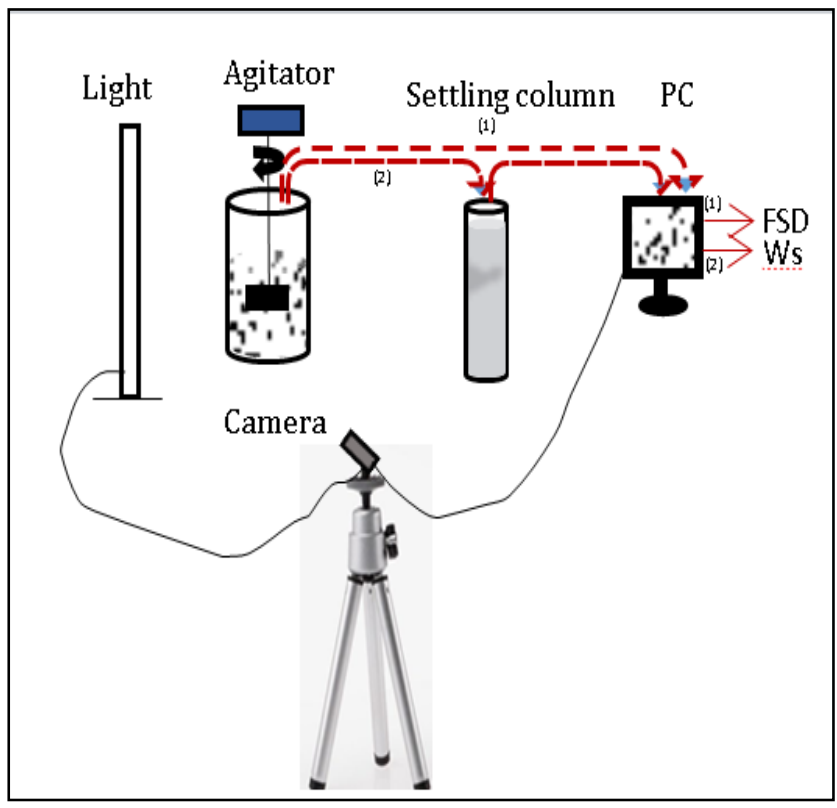

Figure 2. Schematic diagram of PIV system, settling column, sample bowl and stirrer.

\subsection{Instrumentation}

Flocculation experiments were conducted in $1 \mathrm{~L}$ glass beaker of $11 \mathrm{~cm}$ diameter. It was equipped with a variable speed agitator to control turbulence of the flow inside the beaker. A settling column with 
a diameter of $5 \mathrm{~cm}$ and a height of $40 \mathrm{~cm}$ was used to measure the flocs' settling velocities. Flocs were introduced from the top of the settling column filled with water, where the falling flocs were filmed using a PIV system as shown in Figure 2. The PIV system consists of a backlight which is positioned opposite the CCD camera to provide a uniform black background upon which particles appear as white, the CCD camera with $1392 \times 1040$ pixel sensitivity, focal length, $f$, of $9 \mathrm{~mm}$ and a maximum frequency of 30fps $(\Delta \mathrm{t}=1 / 30 \mathrm{~s})$, a Polytec BVS-11 Wotan flash stroboscope and trigger box, fibre optic cable and linelight.

\subsection{Instrument calibration}

Instrument calibration for the flow velocity is necessary to quantify the hydrodynamic shear stress present inside the beaker during the experiment. The angular velocities $(\omega)$ of the agitator were set at 37 , 50, 70, 90 and $110 \mathrm{rpm}$. The turbulence is normally obtained by three velocity components but the radial velocity $\left(w^{\prime}\right)$ was found too small. Therefore, at each rotational speed, the turbulent kinetic energy $(\mathrm{K})$ was measured by considering the tangential and vertical velocity fluctuations $\left(u^{\prime}, v^{\prime}\right)$. The fluctuation velocity can be measured by using the PIV equipment. Since turbulent kinetic energy is defined according to the following equation:

$$
K=\frac{1}{2}\left(\overline{u^{\prime 2}}+\overline{v^{\prime 2}}\right)
$$

The equation (2) is used to determine the turbulent shear stress $\left(T_{s}\right)$ in $\mathrm{N} / \mathrm{m}^{2}$ (Manning 2004a):

$$
T_{s}=0.19 \rho_{w} K
$$

where $\rho_{w}$ is the water density and which was assumed to be $1000 \mathrm{~kg} / \mathrm{m}^{3}$.

The flow velocity was also calculated theoretically by conversion of the angular velocity into the linear velocity.

$$
\mathrm{U}=\frac{\pi D \omega}{60000}
$$

where, $\mathrm{D}$ is the diameter of the beaker $(\mathrm{mm}), \omega$ is the angular velocity $(\mathrm{rpm})$ and $\mathrm{u}$ is a flow velocity $(\mathrm{m} / \mathrm{s})$

Table 3 presents the calculated turbulent shear stresses that correspond to all of the rotational speeds and the experiment (measured) and theoretical (calculated) average flow velocity values. Comparison between the theoretical and experimental flow velocity is shown in Figure 3. The theoretical and measured (using PIV) flow velocities were found to correlate reasonably well with a $\mathrm{R}^{2}$ value of 0.98. This result confirms the accuracy of the PIV camera and the suitability of this method to this novel type of application as also applied by Maggi (2005).

\subsection{Experimental procedures}

This study focuses on the influence of the turbulent shear stress on the floc size and settling velocity.

Table 1. Shear flow parameters with respect to different angular velocities.

\begin{tabular}{cccc}
\hline \multirow{2}{*}{$\begin{array}{c}\text { Angular } \\
\text { velocity }\end{array}$} & \multicolumn{2}{c}{ Flow velocity } & \multirow{2}{*}{$\begin{array}{c}\text { Turbulent } \\
\text { shear stress }\end{array}$} \\
\cline { 2 - 3 } & Measured & Calculated & $\mathrm{N} / \mathrm{m}^{2}$ \\
\hline $\mathrm{rpm}$ & $\mathrm{m} / \mathrm{s}$ & $\mathrm{m} / \mathrm{s}$ & 0.57 \\
37 & 0.10 & 0.08 & 1.70 \\
50 & 0.14 & 0.14 & 3.80 \\
70 & 0.20 & 0.22 & 6.00 \\
90 & 0.26 & 0.21 & 8.50 \\
110 & 0.32 & 0.29 & \\
\hline
\end{tabular}

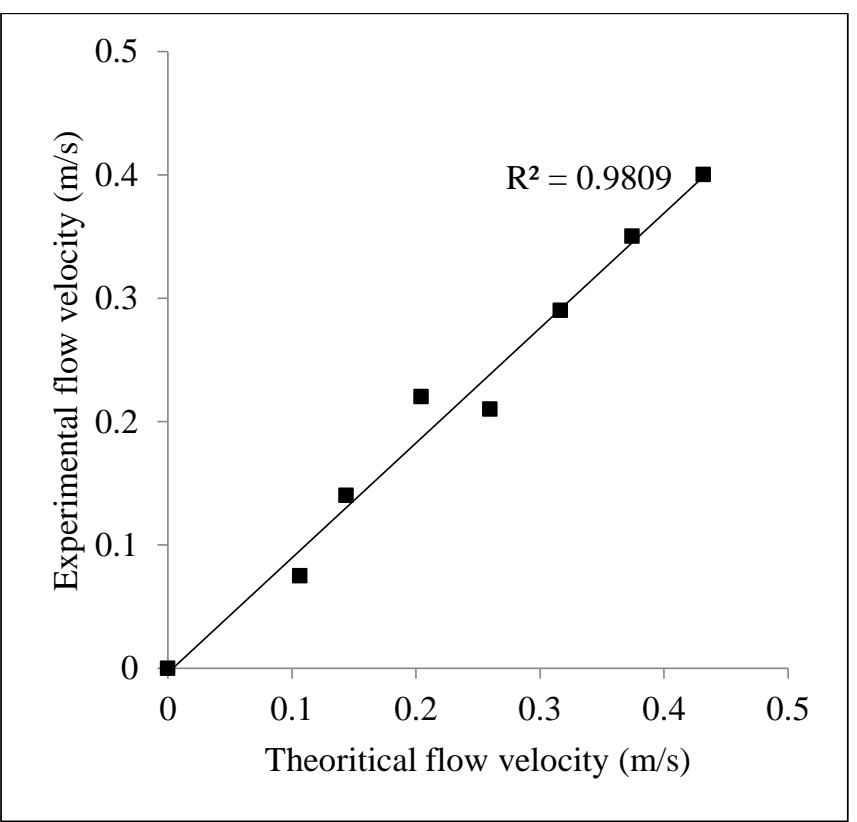

Figure 3. Comparison between experimental and theoretical flow velocities.

The experiments were carried out in two main steps: The first step is to apply the highest tested shear stress of $60 \mathrm{~N} / \mathrm{m}^{2}$ to break down any potential macroflocs in suspension as the initial state; the second step, which is the main testing part, is to run the agitator at a series of rotational speeds to generate the desired turbulent shear stresses, ranging from $0.57 \mathrm{~N} / \mathrm{m}^{2}$ to $8.55 \mathrm{~N} / \mathrm{m}^{2}$ for a duration of $120 \mathrm{~min}$ as suggested by (Mikes et al. 2004; Verney et al. 2009). This is a significant time period for flocculation to occur in natural water bodies (Le Hir et al. 2001), where the average floc size no longer changes after this time. During the experiment, a series of images is recorded from the PIV system at different time steps in order to calculate the floc size distributions over the investigated period. 
To investigate the effect of turbulent shear stress variation on flocs size and settling velocity, 5 laboratory experiments with turbulent shear stresses of $0.57,1.7,3.8,6$ and $8.55 \mathrm{~N} / \mathrm{m}^{2}$ were conducted for the same suspended sediment concentration and salinity, $c=100 \mathrm{mg} / \mathrm{l}$ and $\mathrm{S}=2.5 \mathrm{ppt}$, respectively. These values of salinity and sediment concentration were chosen in this study because they were considered to represent the optimal conditions for flocculation processes. The organic carbon represents $2 \%$. For each test, $10 \mathrm{ml}$ of flocculated sample was then introduced from the top of the settling column. After introduction of the sample into the water column, the flocs were allowed to settle by gravity over a distance of approximately $13 \mathrm{~cm}$ prior to switching the camera on and in order to allow the damping out of any activity from the introduction method.

Another specific set of experiments was conducted in this study to investigate the effect of turbulence over time on the particle size. For this scenario only one parameter was varied at a time, while the other was kept constant. The test was undertaken at salinity of $2.5 \mathrm{ppt}$, sediment concentration of $100 \mathrm{mg} / \mathrm{l}$ and the lowest turbulent shear stress of $0.57 \mathrm{~N} / \mathrm{m}^{2}$ for 2 hours, allowing the floc grow from the initial state to equilibrium size to an equilibrium state (Le Hir et al. 2001; Mikes et al. 2004). Then the turbulent shear stress was increased every hour until reaching $8.55 \mathrm{~N} / \mathrm{m}^{2}$. The test was undertaken at salinity of 2.5 ppt, sediment concentration of $100 \mathrm{mg} / \mathrm{l}$ and the lowest turbulent shear stress of $0.57 \mathrm{~N} / \mathrm{m}^{2}$ for 2 hours. This time is important to allow the floc grow from the initial state to equilibrium size, where the average floc size no longer changed with time (Le Hir et al. 2001; Mikes et al. 2004) stopped at each turbulent shear stress. The agitator was for approximately 3-5 seconds in order to take some images for analysis of the size of the flocs.

\subsection{Image analysis}

The floc size distribution and settling velocity were both obtained from floc image recording and processing. The main five steps in the image processing are needed: (1) selecting the flocs manually at the start and at the end of the sequence by opening images using image editor and paint program; (2) enhancing background (brightness and contrast); (3) removing any noise to make sure the flocs appear in all of the sequential images by opening images using an image editor and the paint program; (4) removing all flocs which are touching the image boundary and are not in focus; and (5) calculating the features of flocs including: sectional area, location and circularity by using the "ImageJ" software. As this method is interactive there is very low risk of errors being made in the determination of the floc paths.
ImageJ was capable of detecting particles larger than $70 \mu \mathrm{m}$ below this limit the pixel resolution of the floc measurement is not consistent and hence the smallest microflocs are not accounted for the description of the floc population during the experiment. Floc size was obtained using the contrast between the dark background and the white silhouettes of the floc. The surface equivalent diameter $\mathrm{d}$ was calculated by converted particle area $(A)$ into equivalent circular diameter (Flory et al. 2004; Mikes et al. 2004; Verney et al. 2009) as:

$$
d=\sqrt{\frac{4 A}{\pi}}
$$

\section{RESULTS AND DISCUSSION}

This section describes the laboratory experiments results of the influence of the turbulent shear stress on floc size distribution (FSD) and their settling velocity.

\subsection{Effect of turbulence on FSD}

The floc size distributions under different shear velocities are shown in Figure 4.

Table 2 shows the size distributions in eight bands. Band 1 represents flocs with a size of less than 100 $\mu \mathrm{m}$, whilst band 8 represents flocs with a size bigger than $700 \mu \mathrm{m}$. Other sizes of the flocs are evenly represented by bands 2 to 7 . For the smallest shear stress $\left(0.57 \mathrm{~N} / \mathrm{m}^{2}\right)$, it can be seen that no particles smaller than $100 \mu \mathrm{m}$ are detected and there is no detection of particles larger than $500 \mu \mathrm{m}$. Whereas, for the shear stress at $8.5 \mathrm{~N} / \mathrm{m}^{2}, 50 \%$ of the floc area have particles with a size of less than $100 \mu \mathrm{m}$ and there is no particle detected larger than $400 \mu \mathrm{m}$. This confirms that higher shear stresses lead to break down of macroflocs into microflocs.

The floc structure are shown in Figure 5, by the SEM photographs at $\eta=0.57 \mathrm{~N} / \mathrm{m} 2$ for sediment concentration of $100 \mathrm{mg} / \mathrm{l}$ and salinity $2.5 \mathrm{ppt}$. The irregular shape floc can be clearly seen in Figure 5. Although, it cannot be directly measured of the floc structure using PIV camera, the fractal dimension of flocs can be determined theoretically using Winterwerp model (Winterwerp 1999). This model was developed based on field and laboratory data, as shown in Figure 6. The experiment data of settling velocity and floc size at different turbulent shear stresses was plotted with Winterwerp model in Figure 6. It is observed that the data match the Winterwerp model adequately. The overall trend of the experiment data points seems slightly steeper than the fit with $\mathrm{nf}=2$. However, when the individual data set are studied, the slope agree better with $\mathrm{nf}=2$ for turbulent shear stress less than $6 \mathrm{~N} / \mathrm{m}^{2}$. It is important to work with 
nf value as the density is more realistic than the stokes law. As in the stokes law the density calculated is based on the assumption of the flocs have a spherical diameter. By knowing nf value from this chart, it will be easy to calculate the floc density from theoretical equation:

$$
\rho_{f}-\rho_{w}=\left(\rho_{s}-\rho_{w}\right)\left(\frac{d^{n f-3}}{d_{i}}\right)
$$

where $\rho_{f}$ is the floc density, $\rho_{w}$ is the water density, $\rho_{s}$ is the mud density, $\mathrm{d}$ is the equivalent spherical diameter, $d_{i}$ is the diameter of the primary particle and $n f$ is the fractal dimension.

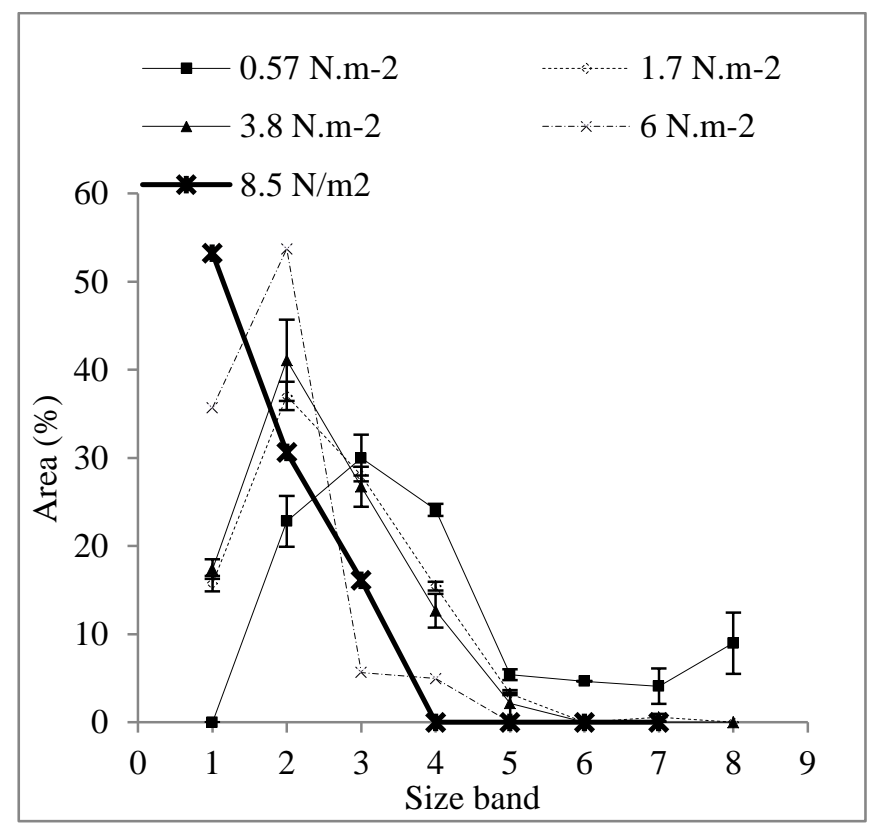

Figure 4. Floc size distribution under different turbulent shear stress including the standard deviation between two runs.

Table 2. The definition of floc size band

\begin{tabular}{lcccccccc}
\hline $\begin{array}{l}\text { Size } \\
\text { band }\end{array}$ & 1 & 2 & 3 & 4 & 5 & 6 & 7 & 8 \\
\hline $\begin{array}{l}\text { Floc size } \\
(\mu \mathrm{m})\end{array}$ & $<$ & $100-$ & $200-$ & $300-$ & $400-$ & $500-$ & $600-$ & $>$ \\
\hline
\end{tabular}

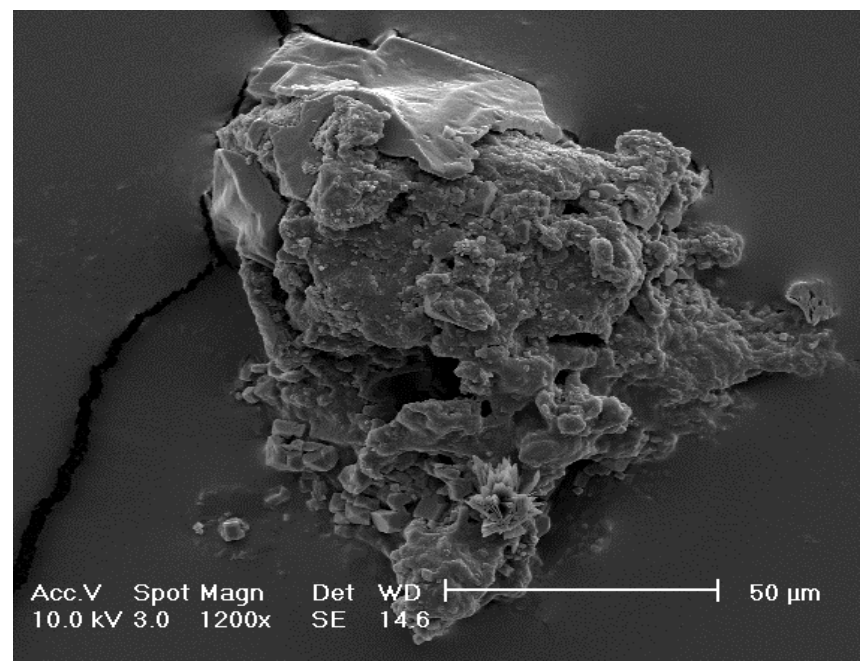

Figure 5. SEM photographs of floc from the experiment at turbulent shear stress of $0.57 \mathrm{~N} / \mathrm{m}^{2}$.

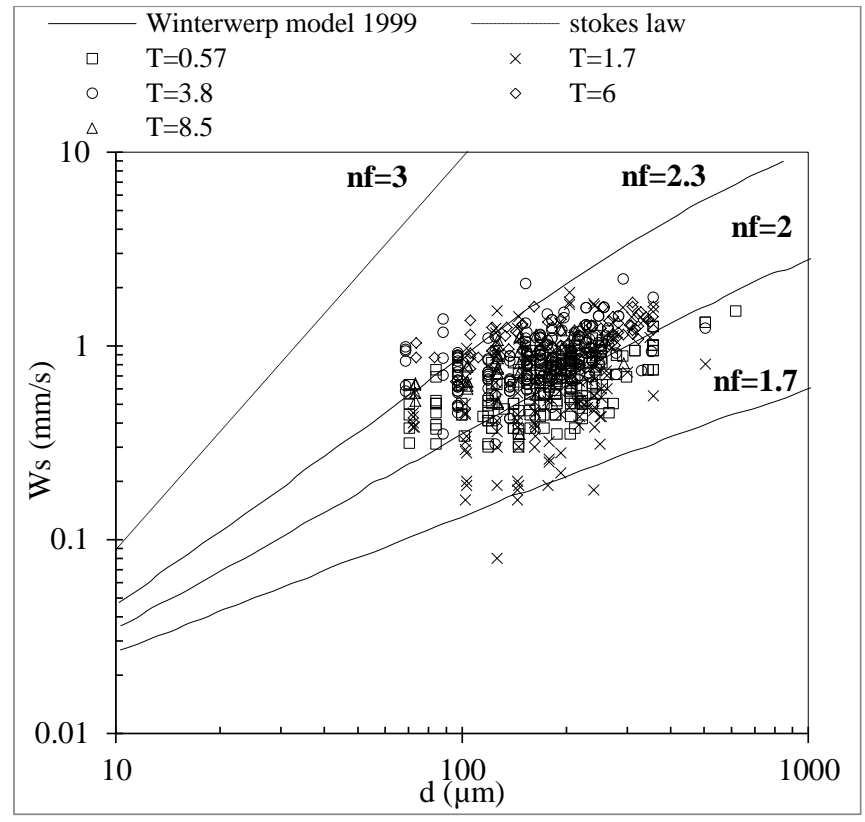

Figure 6. Relation between settling velocity and floc size

\subsection{Effect of turbulence change over time on FSD}

Evidently, turbulence plays an important role on flocculation mechanism. In natural estuarine waters turbulence varies during the tidal cycle (Zhu et al. 2015). This specific scenario was explored in this as the effect of turbulence on FSD over time. An increase of the turbulent shear stress from $0.57 \mathrm{~N} / \mathrm{m}^{2}$ to $8.55 \mathrm{~N} / \mathrm{m}^{2}$ was considered with a constant concentration (c) of $100 \mathrm{mg} / \mathrm{l}$ and salinity (S) of $2.5 \mathrm{ppt}$.

Figure 7 represents the maximum floc size for suspended sediment concentration of $100 \mathrm{mg} / \mathrm{l}$ and salinity of $2.5 \mathrm{ppt}$, as a function of the turbulent shear rate calculated to the corresponding stirring velocity. It is apparent that the turbulent shear stresses ranging from $0.57 \mathrm{~N} / \mathrm{m}^{2}$ to $8.5 \mathrm{~N} / \mathrm{m}^{2}$ cause a breakdown in floc structure rather than enhancing the flocculation processes, causing a decrease of the floc diameter. The floc strength was addressed indirectly when we looked at the effect of maximum floc under different turbulent shear stress as a PIV was incapable of taking directly measurement of the floc strength. This observation is a similar to that given by (Manning and Dyer 1999) who found a decrease in floc size with an increase of the shear velocity of up to $0.3 \mathrm{~N} / \mathrm{m}^{2}$ in their laboratory flume experiments with sediment samples from the Tamer Estuary and sediment concentrations ranging from $80 \mathrm{mg} / \mathrm{l}$ to $200 \mathrm{mg} / \mathrm{l}$.

The results of two tests with different turbulent shear stresses on samples with maximum size flocs are shown in Figure 8.

Two sets of experiments were carried out. In the first set, 5 different turbulent shear stresses were tested in at $0.57,1.7,3.8,6$ and $8.5 \mathrm{~N} / \mathrm{m}^{2}$ ), which represent the variations in the maximum floc size 
over fixed turbulent shear stress. Whereas, in the second set, only one test was run starting at a turbulence of $0.57 \mathrm{~N} / \mathrm{m}^{2}$ for 2 hours initially and then turbulence was increased to $1.7,3.8,6$ and $8.5 \mathrm{~N} / \mathrm{m}^{2}$ at every 1 hour interval which represents the relationship between the maximum floc size and the variation of the turbulent shear stress over time.

Figure 8 clearly shows a large floc size occurred at the lowest speed $\left(0.57 \mathrm{~N} / \mathrm{m}^{2}\right)$. It was found that when turbulence was increased the flocs broke apart which was reflected in a decrease of the maximum diameter from $865 \mu \mathrm{m}$ at $\eta=0.57 \mathrm{~N} / \mathrm{m}^{2}$ to $280 \mu \mathrm{m}$ at $\eta=8.5 \mathrm{~N} / \mathrm{m}^{2}$, of nearly $67.6 \%$.

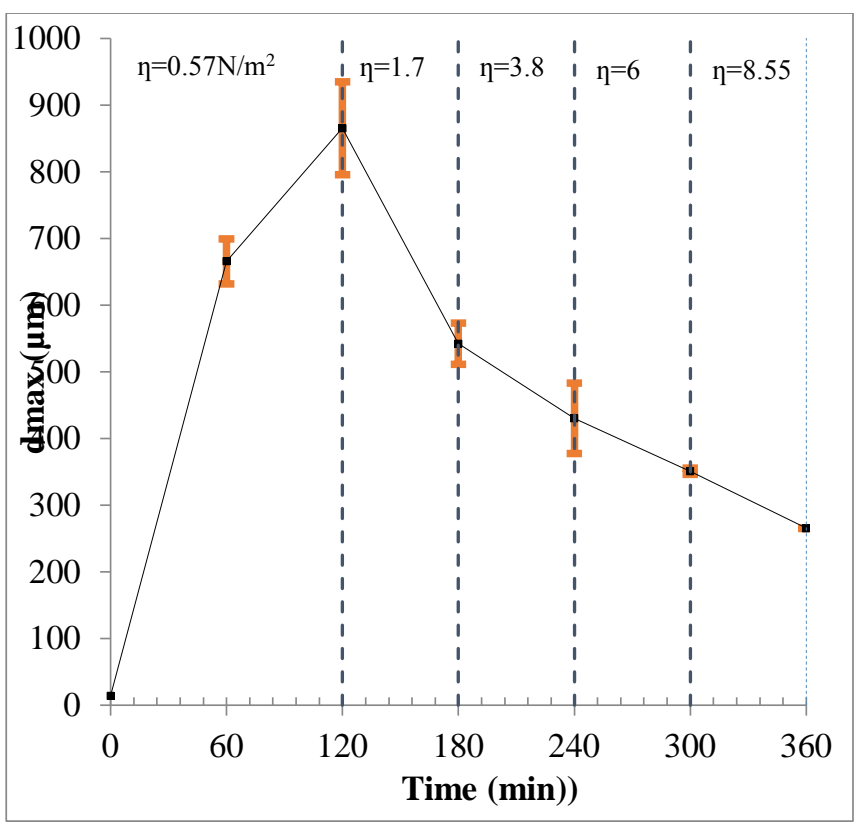

Figure 7. Maximum Floc size changing over time under different turbulent shear stress.

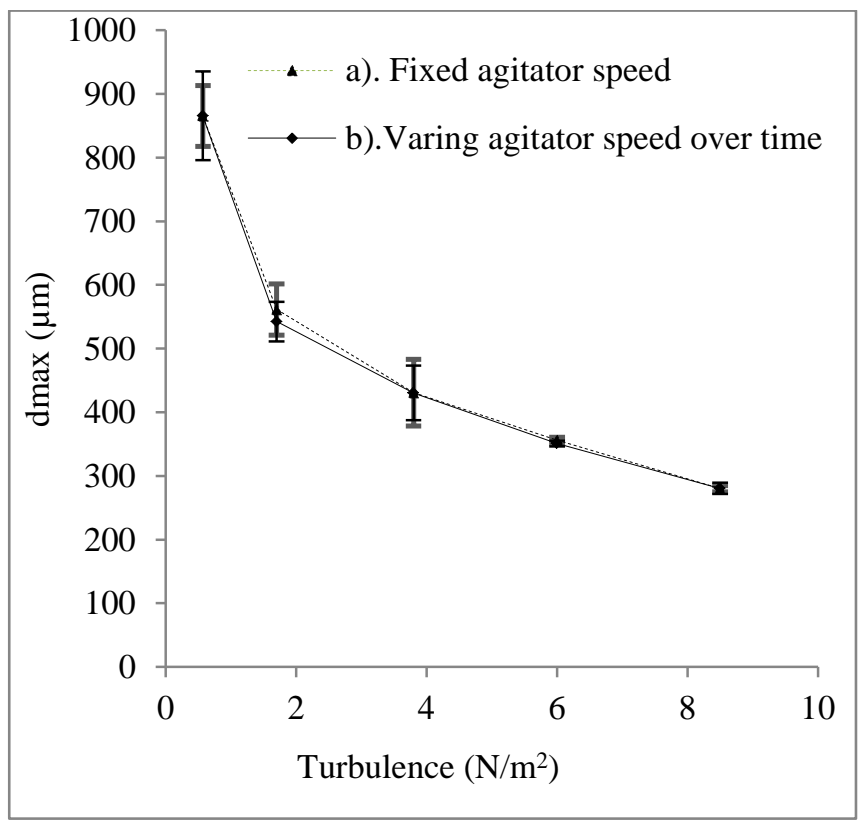

Figure 8. Maximum floc size for: a) fixed agitator speed and b) varying agitator speed over time. The range shows the standard deviation between two runs.
The maximum floc size was found to be the similar with very little differences. This means that the floc size becomes independent to the turbulent shear stress once it is formed during the initial stage.

\subsection{The influence of turbulence on settling velocity}

The settling velocities against floc size for different turbulent shear stresses are displayed in Figure 9. This figure shows that the settling velocity changes from 0.4 to $1.4 \mathrm{~mm} / \mathrm{s}$. The settling velocity changes with both parameters: floc size and turbulence. For a constant shear stress, the settling velocity increased with particle size. The settling velocity increased by almost $45.5 \%$ from $0.6 \mathrm{~m} / \mathrm{s}^{1}$ at turbulent shear stress of $0.57 \mathrm{~N} / \mathrm{m}^{2}$ to reach a maximum value $(1.1 \mathrm{~mm} / \mathrm{s})$ at $\eta=6 \mathrm{~N} / \mathrm{m}^{2}$, followed by a $27 \%$ decrease $(0.8$ $\mathrm{mm} / \mathrm{s})$ at a maximum value of $\eta\left(8.5 \mathrm{~N} / \mathrm{m}^{2}\right)$.

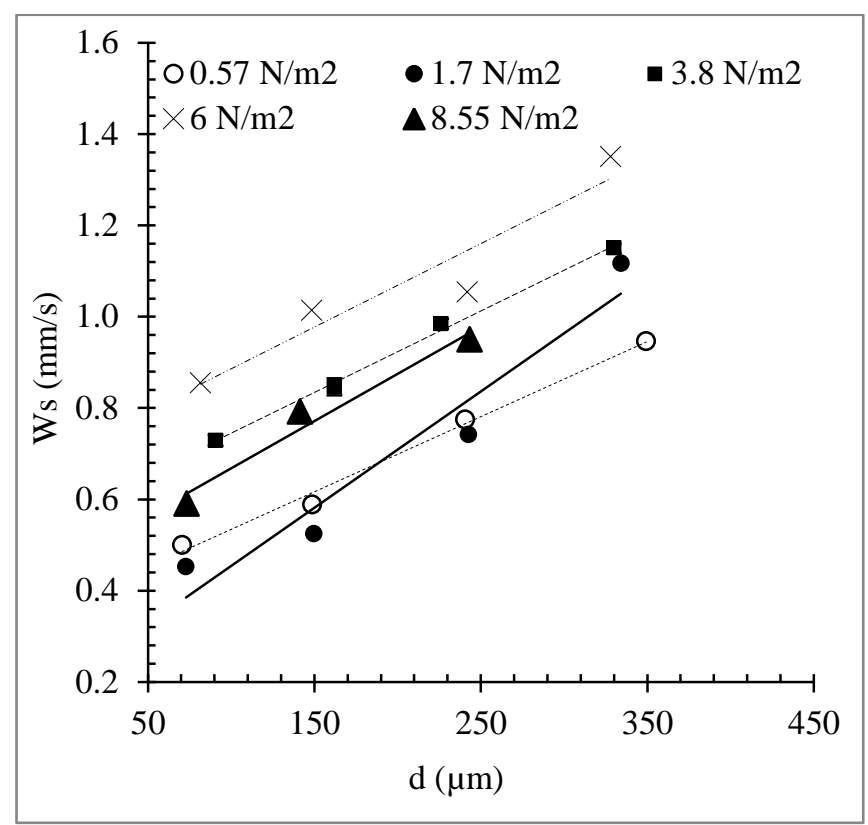

Figure 9. Settling velocity with floc size and for varying turbulent shear stress. The range shows the standard deviation between two runs.

Pejrup and Mikkelsen (2010) showed that the mean settling velocity increases as a function of velocity gradient up to a maximum value of approximately $8.5 \mathrm{~s}^{-1}$, and then starts to decrease. This result was based on data collected by (Pejrup et al. 1997) from Røm $\varnothing$ Dyb where the suspended sediment concentration varied between 20 and $200 \mathrm{mg} / \mathrm{l}$. It was found in this study that for a certain range of settling velocities the increasing floc size can be described by the regression equation in the form of $y=a x+$ $b$. The value for $a$ and $b$ are constant and are found to be dependent on the turbulence. The regression fitness coefficient $\mathrm{R}^{2}$ ranges from 0.9 to 0.99 for the entire range of turbulence. The regression constants and $\mathrm{R}^{2}$ are listed in Table 3. 
Table 3. Settling velocity equations as a function of floc size developed from the experiment.

\begin{tabular}{cccc}
\hline \multirow{2}{*}{$\begin{array}{c}\text { Turbulence } \\
\left(\mathrm{N} / \mathrm{m}^{2}\right)\end{array}$} & \multicolumn{2}{c}{ Regression Constants } & $\mathrm{R}^{2}$ \\
\cline { 2 - 3 } & $a$ & $b$ & \\
\hline 0.57 & 0.0016 & 0.36 & 0.99 \\
1.7 & 0.0025 & 0.20 & 0.93 \\
3.8 & 0.0018 & 0.56 & 0.99 \\
6.0 & 0.0018 & 0.70 & 0.91 \\
8.5 & 0.0020 & 0.46 & 0.96 \\
\hline
\end{tabular}

\section{CONCLUSIONS}

The potential impacts of the turbulent shear stresses on the floc size and settling velocity were assessed in this study using suspended sediment samples taken from the Severn Estuary with well-controlled laboratory experiments. The results demonstrated that for turbulent shear stresses ranging from 0.57 to 8.5 $\mathrm{N} / \mathrm{m}^{2}$, a breakdown in floc structure was occurring by nearly $67.6 \%$.

The results clearly illustrate that the settling velocity increases by almost $45.5 \%$ from $(0.6 \mathrm{~mm} / \mathrm{s})$ at turbulent shear stress of $0.57 \mathrm{~N} / \mathrm{m}^{2}$ to reach a maximum value of $1.1 \mathrm{~mm} / \mathrm{s}$ at turbulent shear stress of 6 $\mathrm{N} / \mathrm{m}$, followed by a $27 \%$ decrease to $0.8 \mathrm{~mm} / \mathrm{s}$ at the maximum turbulent shear stress of $8.5 \mathrm{~N} / \mathrm{m}^{2}$ in the experiments. Additionally, it was found that the relationship between floc size and turbulent shear stresses is independent of the history of the floc formation.

Deposition and resuspension processes in estuaries are strongly dependent on floc size and settling velocity, which depend mainly on the turbulent shear stress. Therefore, the results obtained from this study can be implemented into the numerical models so that flocculation mechanisms (floc size and settling velocity) can be considered more realistically for the field scale, and for the direct impact on morphological and water quality processes.

Representation of these processes in hydrodynamic estuarine models will lead to a better understanding of how to best manage estuarine and coastal waters under future stresses like climate change.

Future work will include applying and refining a numerical model does not have a flocculation processes to include the more complex settling velocity function taking in account density and floc size for different salinity, suspended sediment concentration and turbulent range. This will be the first useful step.

\section{REFERENCES}

Dyer, K. R. and Manning, A. J. 1999. Observation of the size, settling velocity and effective density of flocs, and their fractal dimensions. Journal of Sea Research 41(1-2), pp. 87-95.

Eisma, D. 1986. Flocculation and de-flocculation of suspended matter in

estuaries. Netherlands Journal of Sea Research

20(2-3), pp. 183-199

Fennessy, M. J. et al. 1994. inssev: An instrument to measure the size and settling velocity of flocs in situ. Marine Geology 117(1-4), pp. 107-117.

Flory, E. N. et al. 2004. The relationship between floc area and backscatter during a spring phytoplankton bloom. Deep Sea Research Part I: Oceanographic Research Papers 51(2), pp. 213-223.

Gao, G. et al. 2011. Numerical Modelling SedimentBacteria Interaction Processes in the Severn Estuary. Journal of Water Resource and Protection 3(1), pp. 22-31.

Jonas, P. J. C. and Millward, G. E. 2010. Metals and nutrients in the Severn Estuary and Bristol Channel: Contemporary inputs and distributions. Marine Pollution Bulletin 61(1-3), pp. 52-67.

Kadiri, M. B.-E., B.; Zhou, J.;Falconer,R. 2014. Water Quality Impacts of A Tidal Barrage In the Severn Estuary,UK. In: 10th ISE 2014. Trondheim, Norway.

Kirby, R. 2010. Distribution, transport and exchanges of fine sediment, with tidal power implications: Severn Estuary, UK. Marine Pollution Bulletin 61(1-3), pp. 21-36.

Lafite, R. 2001. Impact de la dynamique tidale sur le transfert de sédiments fins. Université de Rouen.

Le Hir, P. et al. 2001. Fine sediment transport and accumulations at the mouth of the Seine estuary (France). Estuaries 24(6 B), pp. 950-963.

Maggi, F. 2005. Flocculation dynamics of cohesive sediment. University of Technology, Delft.

Manning, A. J. 2001. Study of the effect of turbulence on the properties of flocculated mud University of Plymouth.

Manning, A. J. 2004a. Observations of the Properties of Flocculated Cohesive Sediment in Three Western European Estuaries. Journal of Coastal Research, pp. 70-81.

Manning, A. J. 2004b. The Observed Effects of Turbulence on Estuarine Flocculation. Journal of Coastal Research, pp. 90-104.

Manning, A. J. and Dyer, K. R. 1999. A laboratory examination of floc characteristics with regard to turbulent shearing. Marine Geology 160(1-2), pp. $147-170$.

Manning, A. J. et al. 2004. Flocculation measured by video based instruments in the gironde estuary during the European commission SWAMIEE project. Journal of Coastal Research (SPEC. ISS. 41), pp. 5869.

Manning, A. J. et al. 2013. Flocculation Dynamics of Mud: Sand Mixed Suspensions.

McLaren, P. et al. 1993. Sediment dynamics of the Severn Estuary and inner Bristol Channel. Journal Geological Society (London) 150(3), pp. 589-603.

Mikes, D. et al. 2004. "Controlling factors in estuarine flocculation processes : experimental results with material from the Seine Estuary, Northwestern France.". Journal of coastal research 41, pp. 82-89. 
Pejrup, M. et al. 1997. A fine-grained sediment budget for the Sylt-Røm $\varnothing$ tidal basin. Helgoländer Meeresuntersuchungen 51, pp. pp. 253-268.

Pejrup, M. and Mikkelsen, O. A. 2010. Factors controlling the field settling velocity of cohesive sediment in estuaries. Estuarine, Coastal and Shelf Science 87(2), pp. 177-185.

Serra, T. and Casamitjana, X. 1998. Structure of the Aggregates During the Process of Aggregation and Breakup Under a Shear Flow. Journal of Colloid and Interface Science 206(2), pp. 505-511.

Serra, T. et al. 1997. Aggregation and Breakup of Particles in a Shear Flow. Journal of Colloid and Interface Science 187(2), pp. 466-473.

Syvitski, J. P. M. et al. 1995. In-situ characteristics of particles settling within a deep-water estuary. Deep Sea Research Part II: Topical Studies in Oceanography 42(1), pp. 223-256.

van Leussen, W. and Cornelisse, J. M. 1996. The underwater video system VIS. Journal of Sea Research 36(1-2), pp. 77-81.

Verney, R. et al. 2009. Flocculation potential of estuarine particles: The importance of environmental factors and of the spatial and seasonal variability of suspended particulate matter. Estuaries and Coasts 32(4), pp. 678-693.

Wollast, R. 1988. The Scheldt Estuary. W. Salomon, B.L. Bayne, E.K. Duursma, U. Förstner (Eds.), Pollution of the North Sea, an assessment, Springer-Verlag, pp. 183-193.

Zhu, Z. et al. 2015. Fractal Dimension of Cohesive Sediment Flocs at Steady State under Seven Shear Flow Conditions. Water 7(8), p. 4385. 